\title{
Preliminary In Vitro Biological and Phytochemical Screenings of Parmentiera cereifera Seem
}

\author{
Md. Reyad-ul-Ferdous ${ }^{1}$, Ridwan Bin Rashid ${ }^{2}$, Md. Al Amin Sikder ${ }^{3}$, Fahima Aktar ${ }^{3}$ and \\ Mohammad A. Rashid ${ }^{3}$ \\ ${ }^{1}$ Department of Pharmacy, State University of Bangladesh, Dhaka, Bangladesh \\ ${ }^{2}$ Department of Microbiology, University of Dhaka, Dhaka, Bangladesh \\ ${ }^{3}$ Department of Pharmaceutical Chemistry, Faculty of Pharmacy, University of Dhaka, Dhaka, Bangladesh
}

\begin{abstract}
In this present study, the leaf extracts of Parmentiera cereifera were subjected to a comparative evaluation of the antioxidant capacities, phenol and polyphenols content, membrane stabilization, thrombolytic, antimicrobial activities and cytotoxicity to brine shrimps (Artemia salina). When the DPPH (1,1- Diphenyl-2-picryl hydrazyl) radical scavenging effect was determined spectrophotometrically significant radical scavenging property was observed in crude methanol extract (ME) with $\mathrm{IC}_{50}$ of $21.95 \mu \mathrm{g} / \mathrm{ml}$. Here, butylated hydroxytoluene (BHT) and ascorbic acid (ASA) were used as standard antioxidants. The phenol and polyphenol content of the extractives varied between 56.84 to $89.58 \mathrm{mg}$ of GAE/gm of dried extract. The thrombolytic and membrane stabilizing activities were assessed by using human erythrocyte and the results were compared with standard streptokinase (SK) and standard anti-inflammatory drug, acetyl salicylic acid (ASA), respectively. The extracts demonstrated significant toxicity to A. salina with $\mathrm{LC}_{50}$ values ranging from 6.07 to $7.83 \mu \mathrm{g} / \mathrm{ml}$ as compared to standard Vincristine sulphate (VS, $\mathrm{LC}_{50}$ value $0.45 \mu \mathrm{g} / \mathrm{ml}$ ). On the other hand, the chloroform soluble fraction (CSF) of methanol extract revealed moderate antibacterial activity against some microorganisms used in the screening. Preliminary phytochemical investigation suggested the presence of flavonoids, saponins, tannins, triterpenoids and steroids.
\end{abstract}

Key words: Parmentiera cereifera, membrane stabilizing, free radical scavenging, thrombolytic

\section{Introduction}

Parmanteira cereifera (commonly- Candle tree) is a small tree with rough bark belonging to the family Bignoniaceae. The leaves are oblong and acuminate. The flowers are cauliflorous, nocturnal, white, slightly fragrant and calyx spathaceous. The fruits and seeds of this tree are berry pale yellow, pendent, candle-like, smooth, edible and used as fodder source. The tree is native to Panama and cultivated for ornamental uses in many tropical countries (Van Steenis, 1977; Madulid, 2000).

As a part of our continuing studies on medicinal plats of Bangladesh, the organic soluble materials of leaf of $P$. cereifera were evaluated for antioxidant activity in terms of free radical scavenging activity using DPPH and poly phenolic composition, membrane stabilization, thrombolysis, cytotoxicity and antimicrobial activities as well as for determining phytoconstituents for the first time.

\section{Materials and Methods}

Plant materials: The leaves of $P$. cereifera were collected from Mirpur Botanical Garden, Dhaka, Bangladesh, in November 2011. A voucher specimen for this plant has been maintained in Bangladesh National Herbarium, Dhaka, Bangladesh (Accession no.36569). The sun dried and powdered leaf (500 gm) of $P$. cereifera was macerated in $2.5 \mathrm{~L}$ of methanol for 7 days and then filtered through a cotton plug followed by Whatman filter paper number 1 . The extract was concentrated with a rotary evaporator at low temperature $\left(40-45^{\circ} \mathrm{C}\right)$ and reduced pressure. The concentrated methanolic extract (ME) was partitioned by modified Kupchan method (Van Wagenen et al., 1993) and the resultant partitionates i.e., pet-ether (PESF), carbon tetrachloride (CTCSF), chloroform (CSF) and aqueous (AQSF) soluble materials were used for the experimental processes.

Correspondence to: Mohammad A. Rashid, E-mail address: rashidma@univdhaka.edu 
Streptokinase (SK): Commercially available lyophilized Altepase (Streptokinase) vial (Beacon pharmaceutical Ltd.) of 15, 00,000 I.U., was collected and $5 \mathrm{ml}$ sterile distilled water was added and mixed properly. This suspension was used as a stock from which $100 \mu \mathrm{l}$ (30,000 I.U) was used for in vitro thrombolysis.

Blood sample: Blood $(\mathrm{n}=5)$ was drawn from healthy human volunteers without a history of oral contraceptive or anticoagulant therapy and $1 \mathrm{ml}$ of blood was transferred to the previously weighed microcentrifuge tubes and was allowed to form clots.

Thrombolytic activity: The thrombolytic activity of all extracts was evaluated by the method developed by Daginawala (2006) and slightly modified by Kawsar et al. (2011) using streptokinase (SK) as the standard.

Membrane stabilizing activity: The membrane stabilizing activity of the extractives was assessed by using hypotonic solution and heat-induced hemolysis of human erythrocyte by following standard protocol developed by Shinde et al. (1999) and modified by Sikder et al. (2011).

Total phenolics analysis: Total phenolic content of leaves of $P$. cereifera extractives was measured employing the method described by Skerget et al, (2005) involving Folin-Ciocalteu reagent as oxidizing agent and gallic acid as standard.

Brine shrimp lethality bioassay: This technique was applied for the determination of general toxic property of the plant extractives using method Meyer et al., 1982 and MacLaughlin et al., 1998 against Artemia salina in a 1day in vivo assay. Vincristine sulphate was used as positive control.

Antimicrobial activity: The antimicrobial screening, which is the first stage of antimicrobial drug discovery, was performed by the disc diffusion method (Ayafor, 1972) against thirteen bacteria (Table 3) collected as pure cultures from the Institute of Nutrition and Food Science (INFS), University of Dhaka, Bangladesh. Standard disc of Ciprofloxacin (30 $\mu \mathrm{g} /$ disc) and blank discs (impregnated with solvents followed by evaporation) were used as positive and negative control, respectively. The antimicrobial activity of the test agents was determined by measuring the diameter of zone of inhibition expressed in mm (Bauer et al., 1966)
Free radical scavenging activity: The free radical scavenging activity of the crude methanol extract (ME) was evaluated by the published method (Choi et al., 2000; Desmarchelier et al., 1997). DPPH was used to evaluate the free radical scavenging activity (antioxidant potential).

Preliminary phytochemical screening: One gram of the methanol extract of $P$. cereifera was dissolved in 100 $\mathrm{ml}$ of methanol and was subjected to preliminary phytochemical screenings for determining nature of phytoconstituents (Harbone, 1998; Kokate, 2001).

\section{Results and Discussion}

The methanol extract of $P$. cereifera and its different partitionates, at concentration $1.0 \mathrm{mg} / \mathrm{mL}$, were tested against lysis of human erythrocyte membrane induced by hypotonic solution as well as heat, and compared with the standard acetyl salicylic acid (ASA) $(0.10 \mathrm{mg} / \mathrm{ml})$ (Table 1). In hypotonic solution induced condition the chloroform soluble fraction (CSF) inhibited $69.41 \%$ whereas aqueous soluble fraction (AQSF) inhibited $67.39 \%$ haemolysis of RBC as compared to $71.9 \%$ inhibition by ASA (0.10 $\mathrm{mg} / \mathrm{mL}$ ). On the other hand, during heat induced condition different organic soluble materials of $P$. cereifera i.e. AQSF, CSF, CTCSF and PESF demonstareted 43.28\%, $43.16 \%, 32.14 \%$ and $2.85 \%$ inhibition of hemolysis of RBCs, respectively whereas ASA inhibited 42.12\%.

As a part of discovery of cardio-protective drugs from natural sources the extractives of $P$. cereifera were assessed for thrombolytic activity and the results are presented in Table 2. Addition of $100 \mu \mathrm{l} \mathrm{SK}$, a positive control (30,000 I.U.), to the clots and subsequent incubation for 90 minutes at $37^{\circ} \mathrm{C}$, showed $66.77 \%$ lysis of clot. At the same time, distilled water was treated as negative control which exhibited negligible lysis of clot (3.87\%). In this study, the chloroform soluble fraction (CSF) exhibited highest thrombolytic activity (50.82\%). However, significant thrombolytic activity was demonstrated by the crude methanol extract of $P$. cereifera (41.24\%).

All the partitionates of extract of leaves of $P$. cereifera were tested for total phenolic content. Among all extractives the highest phenolic content was found in PESF (89.58 $\mathrm{mg}$ of GAE/gm of extractives) followed by CTCSF (87.89 mg of GAE/gm of extractives). Significant amount of phenolic compounds were also present in ME 
(73.28 mg of GAE/gm of extractives), CSF (59.94 mg of GAE/gm of extractives) and AQSF (56.84 mg of GAE/ gm of extractives) (Table 2).

The methanol extract of $P$. cereifera was subjected to free radical scavenging activity using DPPH by using ascorbic acid (ASA) and tert-butyl-1-hydroxytoluene (BHT) as reference standards (Table 2). In this investigation, the methanol extract (ME) showed significant free radical scavenging activity with $\mathrm{IC}_{50}$ value of $21.95 \mu \mathrm{g} / \mathrm{ml}$.
Table 1. Effect of extractives of $P$. cereifera on hypotonic solution and heat-induced haemolysis of RBCs

\begin{tabular}{llcc}
\hline Sample code & Sample code & \multicolumn{2}{c}{ \% inhibition of haemolysis } \\
\cline { 3 - 4 } & & $\begin{array}{c}\text { Heat } \\
\text { induced }\end{array}$ & $\begin{array}{c}\text { Hypotonic } \\
\text { solution induced }\end{array}$ \\
\hline Hypotonic medium & $50 \mathrm{mM}$ & -- & -- \\
ME & $1 \mathrm{mg} / \mathrm{ml}$ & $45.99 \pm 4.06$ & $53.59 \pm 3.15$ \\
PESF & $1 \mathrm{mg} / \mathrm{ml}$ & $2.85 \pm 0.95$ & $4.67 \pm 1.05$ \\
CTCSF & $1 \mathrm{mg} / \mathrm{ml}$ & $32.14 \pm 3.55$ & $8.57 \pm 1.81$ \\
AQSF & $1 \mathrm{mg} / \mathrm{ml}$ & $43.28 \pm 4.31$ & $67.39 \pm 3.45$ \\
CSF & $1 \mathrm{mg} / \mathrm{ml}$ & $43.16 \pm 3.25$ & $69.41 \pm 2.56$ \\
Acetyl salicylic acid & $0.10 \mathrm{mg} / \mathrm{ml}$ & $42.12 \pm 1.05$ & $71.9 \pm 1.53$ \\
\hline
\end{tabular}

Table 2. Total phenolic content, free radical scavenging activity and thrombolytic and cytotoxic activities of different fractions of $P$. cereifera

\begin{tabular}{ccccc}
\hline Sample & $\begin{array}{c}\text { Total Phenolic Content } \\
(\mathrm{mg} \text { of GAE/gm of dried extract) }\end{array}$ & $\begin{array}{c}\text { Free radical scavenging activity } \\
\left(\mathrm{IC}_{50} \mu \mathrm{g} / \mathrm{ml}\right)\end{array}$ & $\begin{array}{c}\text { Thrombolytic activity } \\
(\% \text { of lysis) }\end{array}$ & $\begin{array}{c}\text { Cytotoxic activity } \\
\left(\mathrm{LC} \mathrm{C}_{50} \mu \mathrm{g} / \mathrm{ml}\right)\end{array}$ \\
\hline VS & - & - & - & $0.45 \pm 0.15$ \\
ME & $73.28 \pm 0.95$ & $21.95 \pm 0.45$ & $41.24 \pm 1.40$ & $6.67 \pm 0.17$ \\
PESF & $89.58 \pm 1.65$ & - & $18.26 \pm 1.60$ & $6.66 \pm 0.08$ \\
CTCSF & $87.89 \pm 1.05$ & - & $30.57 \pm 2.57$ & $6.22 \pm 0.15$ \\
CSF & $59.94 \pm 2.41$ & - & $50.82 \pm 2.90$ & $7.83 \pm 0.29$ \\
AQSF & $56.84 \pm 1.90$ & - & $20.63 \pm 0.69$ & $6.07 \pm 0.11$ \\
SK & - & - & $66.77 \pm 1.59$ & - \\
Water & - & - & $3.87 \pm 0.13$ & - \\
BHT & - & $23.50 \pm 0.82$ & - & - \\
ASA & - & $5.8 \pm 0.21$ & - & - \\
\hline
\end{tabular}

VS = Vincristine sulphate; $\mathrm{ME}=$ Methanolic extract; PESF = Pet-ether soluble fraction; CTCSF = Carbon tetrachloride soluble fraction; $\mathrm{CSF}=$ chloroform soluble fraction; $\mathrm{AQSF}=$ Aqueous soluble fraction of the methanolic extract of $P$. cereifera. SK $=$ Streptokinase; ASA = Ascorbic acid; BHT = tert-butyl-1-hydroxytoluene

Table 3. Antimicrobial activity of $P$. cereifera extractives

\begin{tabular}{lcccccc}
\hline \multicolumn{7}{c}{ Test sample } \\
\multicolumn{7}{c}{ Diameter of zone of inhibition (mm) } \\
\hline Test microorganisms & ME & PESF & CTCSF & CSF & AQSF & Ciprofloxacin \\
\hline Bacillus cereus & $8.55 \pm 1.65$ & - & - & $9.33 \pm 1.53$ & - & $46.3 \pm 1.49$ \\
B. megaterium & $14.55 \pm 1.53$ & - & - & $15.33 \pm 1.53$ & - & $40.3 \pm 1.55$ \\
B. subtilis & $10.66 \pm 2.50$ & - & - & $12.66 \pm 1.06$ & - & $41.6 \pm 2.35$ \\
Staphylococcus aureus & $11.75 \pm 2.55$ & - & - & $13.67 \pm 1.08$ & - & $46.3 \pm 1.24$ \\
Sarcina lutea & $15.55 \pm 2.35$ & - & - & $16.33 \pm 1.52$ & - & $50.3 \pm 0.89$ \\
Escherichia coli & $13.55 \pm 2.55$ & - & - & $14.33 \pm 1.52$ & - & $46.3 \pm 0.94$ \\
Pseudomonas aeruginosa & $11.45 \pm 1.65$ & - & - & $12.33 \pm 2.52$ & - & $44.0 \pm 2.8$ \\
Salmonella paratyphi & $11.75 \pm 3.55$ & - & - & $13.33 \pm 2.52$ & - & $46.6 \pm 1.23$ \\
S. typhi & - & - & - & - & - & $45.6 \pm 1.29$ \\
Shigella boydii & $14.25 \pm 2.55$ & - & - & $15.33 \pm 1.53$ & - & $51.0 \pm 1.41$ \\
S. dysenteriae & $11.55 \pm 3.25$ & - & - & $12.67 \pm 1.08$ & - & $48.0 \pm 2.82$ \\
Vibrio mimicus & $10.25 \pm 1.75$ & - & - & $11.33 \pm 2.51$ & - & $48.3 \pm 1.32$ \\
V. parahaemolyticus & $9.55 \pm 2.75$ & - & - & $11.67 \pm 3.05$ & - & $42.3 \pm 1.68$ \\
\hline
\end{tabular}

The average values of three calculations are presented as mean \pm S.D. (standard deviation)

$\mathrm{ME}=$ Methanolic extract; $\mathrm{PESF}=$ Pet-ether soluble fraction; $\mathrm{CTCSF}=$ Carbon tetrachloride soluble fraction; $\mathrm{CSF}=$ Chloroform soluble fraction; AQSF =Aqueous soluble fraction of the methanolic extract of $P$. cereifera. 
In the brine shrimp lethality bioassay, the $\mathrm{LC}_{50}$ values of ME, PESF, CTCSF, CSF and AQSF of P. cereifera were found to be $6.67,6.66,6.22,7.83$ and $6.07 \mu \mathrm{g} / \mathrm{ml}$, respectively (Table 2).

The crude extract and its different partitionates when subjected to antimicrobial screening at $400 \mu \mathrm{g} /$ disc the crude methanol extract and its chloroform soluble partitionate (CSF) revealed antimicrobial activity against the tested microorganisms having the zone of inhibition ranging from 9.33 to $16.33 \mathrm{~mm}$ (Table 3).

In preliminary phytochemical screening, the methanol extract of leaf of $P$. cereifera demonstrated the presence of flavonoids, saponins, tannins, triterpenoids and steroids (Table 4).

Table 4. Analysis of phytochemicals in the methalol extract of $p$. cereifera

\begin{tabular}{lc}
\hline Phytochemicals & Result \\
\hline Flavonoids & + \\
Saponins & + \\
Tannins & + \\
Triterpenoids & + \\
Steroids & + \\
\hline
\end{tabular}

$+=$ Presence

\section{References}

Ayafor, J.F. 1972. Limonoids and phytol derivatives from Cedrela sinensis. Tetrahedron., 28, 9343.

Bauer, A.W., Kirby, W.M.M., Sherries, J.C. and Tuck, M. 1966. Antibiotic susceptibility testing by a standardized disc diffusion method. Am. J. Clin. Pathol., 45, 493-496.

Choi, H.Y., Jhun, E.J., Lim, B.O., Chung, I.M., Kyung, S.H. and Park, D.K. 2000. Application of flow injectionchemilumineacence to the study of radical scavenging activity in plants. Phytother Res., 14, 250-253.

Daginawala, H.F., Prasad, S., Kashyap, R.S., Deopujari, J.Y., Purohit, H.J. and Taori, G.M. 2006. Development of an in vitro model to study clot lysis activity of thrombolytic drugs. Thrombosis J., 4, 14.
Desmarchelier, C., Repetto, M., Coussio, J., Liesuy, S. and Ciccia, G. 1997. Antioxidant and prooxidant activities in aqueous extracts of Argentine plants. Int J Pharmacog., 35, 116-120.

Harborne, J.B. 1998. Phytochemical methods. A guide to modern techniques of plant analysis. $3^{\text {rd }}$ edn., Chapman and Hall int Ed., New York.

Kawsar, M.H., Sikder, M.A., Rana, M.S., Nimmi, I. and Rashid, M.A. 2011. Studies of Thrombolytic and cytotoxic properties of two asteraceous plants of Bangladesh. Bang. Pharm. J., 14, 103-106.

Kokate, C.K. 2001. Pharmacognosy $16^{\text {th }}$ edn. Nirali prakashani, Mumbai India.

Madulid, D.A. 2000. Pictorial cyclopedia of Philippine ornamental plant. Second edtion. Bookmark, Inc.:120.

McLaughlin, J.L., Anderson, J.E. and Rogers, L.L. 1998. The use of biological assays to evaluate botanicals. Drug Infor. J., 32, 513-524.

Meyer, B.N., Ferrigni, N.R., Putnam, J.E., Jacobsen, J.B., Nicholsand, D.E. and Mclaughlin, J.L. 1982. Brine shrimp; a convenient general bioassay for active plant constituents. Planta Med., 45, 31-34.

Shinde, U.A., Phadke A.S., Nair, A.M., Mungantiwar, A.A., Dikshit, V.J. and Saraf, M.N. 1999. Membrane stabilizing activity - a possible mechanism of action for the antiinflammatory activity of Cedrus deodara wood oil. Fitoterapia, 70, 251-257.

Sikder, M.A., Rahman, M.A., Kaisar M.A., Rahman, M.S., Hasan, C.M. and Rashid, M.A. 2011. In vitro Antioxidant, reducing power, free radical scavenging and membrane stabilizing activities of seeds of Syzygium cumini L.. Lat. Am. J. Pharm., 30, 781-785.

Skerget, M., Kotnik, P., Hadolin, M., Hras, A., Simonic, M. and Knez, Z. 2005. Phenols, proanthocyanidins, flavones and flavonols in some plant materials and their antioxidant activities. Food. Chem., 89, 191-198.

Van Steenis, C.G.G.J. 1977. Bignoniaceae. In Flora Malesiana ser. I, 8, 114-186.

Van Wagenen, B.C., Larsen, R., Cardellina, J.H., Ran dazzo, D., Lidert, Z.C. and Swithenbank, C. 1993. Ulosantoin, a potent insecticide from the sponge Ulosa ruetzleri. J. Org. Chem. 58, 335-337. 